\title{
Correspondence
}

To the Editors:

\section{Special seating service for children with disabilities}

\author{
Sri Lanka Journal of Child Health, 2003; 32: 27-8
}

The Rheumatology and Rehabilitation Hospital Ragama (RRH) has introduced a special seat (with or without wheels $\}$ for children with cerebral palsy and other childhood disabilities. The technology and guidance were given by a British Non Governmental Organisation (NGO) by the name "Motivation", a registered charity in United Kingdom.

The members of the "Motivation" team are a physiotherapist, an occupational therapist, a seating therapist, a speech and language therapist and the technical staff. They applied their specialist knowledge and skills to design a low cost seating system for children with disabilities using locally available materials. They have trained a local therapy team and a technical team to prescribe and fit special seating system and any additional therapeutic devices.

The Motivation multidisciplinary team has prepared and run a training programme at $\mathrm{RRH}$ for therapists working with children. The aim of this training programme was to increase the therapist's skills in developing the life skills of children with disabilities. Life skills mean purposeful and meaningful activities to increase skills and perform eating; drinking; communicating and independence. Our trainers have completed the course successfully and now they work with children with disabilities and the seating therapist does the necessary prescribing and fitting of special seats.

The Ministry of Health has not yet allocated necessary funds for this project at RRH. Therefore we are unable to offer this service free of charge. Spinal Injury Association (SIA), a RRH based Sri Lankan $\mathrm{NGO}$, is given the responsibility of managing the workshop in accordance with the memorandum of understanding (MOD) signed by Ministry of Health and "Motivation".

\section{What is special seating?}

Many children with disabilities are unable to sit without support. They may spend long periods of time lying on one side or sitting in a bad position. This will cause secondary disabilities such as muscle contractures which will lead to postural deformities.
These children need a special seat which will give them more support than a standard chair or wheel chair.

This seat, with or without wheels, has function. activity and communication devices to facilitate the life skills of children. It has a book stand, angled work surface, horizontal and vertical grab bars, activity frame and a communication book. The chair will give more support to the child and he can sit upright and interact with the world around him. Specially designed angled work surface helps him to communicate with his friends, family and teachers. It will also enable them for feeding, drinking and learning activities. The chair is light and easy to manoeuvre around the house and is made of locally available materials. Repairs can be done at any workshop in the island at a low cost. It is made in three standard sizes called G1, G2 and G3.

\section{What are the conditions that require special seating?}

1. Cerebral palsy (CP). Not all children with $\mathrm{CP}$ need a special seat. Those who have difficulties in maintaining balance, posture, mobility and communication need a special seat.

2. Spina bifida. Usually they are normal in intelligence but they may have problems with mobility and bladder/bowel control. The extent of severity depends on the size of the lesion. Most of them are having paraplegia and need special seat with wheels to maintain the balance and mobility.

3. Duchenne muscular dystrophy. The gradual weakness and wasting of skeletal muscles cause inability to perform activities of daily living. There is no cure for this condition at present and regular physiotherapy and occupational therapy are required to maintain their independence as long as possible. They need a special seat with wheels for mobility and to maintain correct posture. 


\section{What are the benefits of special seat?}

- Supports them for a good position.

- Reduces secondary complications such as contractures and bony deformities.

- Improves functions.

- Maintains mobility.

\section{How to access the service?}

Any medical officer can refer suitable children to our general medical clinic which is held on Wednesdays and Fridays in the mornings. The patients are screened in the clinic and those who need special seats are enlisted in our seating clinic waiting list.

Seating clinics are held on the first Friday of the month at RRH. It is a joint clinic run by paediatrician and rheumatologist. In the same clinic seating therapist assesses the suitability and size of the chair needed. The social service officer does a more detail financial screening to identify the amount the family is able to contribute towards a seat. The family return to the seating therapist with the above information and the following decisions are made:

- The size of the seat.

- The date of admission.

The child is booked into the seating clinic diary to be admitted for one month at RRH to receive a seat.

The cost of a chair is dependent on the size of the chair.
G 1 Rupees 13,000
G 2 - Rupees 19,000
G 3 - Rupees 21,000

If the parent's financial situation is good or if they are covered by an insurance scheme, then they have to pay the total cost of the chair, but if the parents are from a poor socioeconomic background, they have to pay a minimum amount of Rs 3500/- or Rs 5000/only. The balance is funded by the SIA.
The payments have to be made to the SIA office and the receipts produced when they come for admission. Those who have not made the payment will be given another appointment for admission when they are ready with the payment.

\section{How does the special seating service work?}

Eight suitable children from the waiting list will be admitted at the beginning of the month to the paediatric ward at RRH for one month hospital stay. During this period they receive intensive therapy from a multidisciplinary team. The team specifically concentrates on improving purposeful and meaningful activities to upgrade the life skills and independence of a disabled child.

Life skills are as follows:

- Communication

- Self care

- Hand skills

- Maintaining the posture and balance

- Understanding and learning about the world around them

- Eating and drinking.

Some of these disabled children may have other medical complications such as epilepsy, hearing and visual problems and these children are referred to relevant specialties at Teaching Hospital Ragama.

Once the seat has been assembled, the child is trained with their parents or carer on how to look after the seat and for some children this will include basic wheel chair skills too.

At the end of the month the child is discharged with special seat and if he needs a further session of therapy, an appointment is given to come as an out patient. Every child who received a seat gets an appointment for a review at the clinic six months later. At this appointment both the child and the seat are examined and if the child is grown the seat is adjusted accordingly.

\section{Lilani Panangala}

Consultant Rheumatologist, Rheumatology and Rehabilitation Hospital, Ragama 